\title{
Un caz rar de hemoragie cerebrală la un prematur care prezintă coarctație de aortă
}

\author{
Andreea Cerghit Paler ${ }^{1}$, Dorottya Miklosi ${ }^{1}$, Liliana Gozar², Rodica Togănel², \\ Amalia Făgărășan ${ }^{2}$, Daniela Toma ${ }^{1}$ \\ ${ }^{1}$ Cardiologie Pediatrică, Institutul de Urgenţă pentru Boli Cardiovasculare şi Transplant, \\ Tg. Mureș, România \\ ${ }^{2}$ Cardiologie Pediatrică, Universitatea de Medicină, Farmacie, Ştiinţă şi Tehnologie \\ "George Emil Palade", Tg. Mureș, România
}

\begin{abstract}
REZUMAT
Introducere. Coarctația de aortă (CoA) este prezentă la 6-8\% dintre pacientii cu boală congenitală cardiacă, cu o incidență de 4/10.000 nou-născuți vii. Poate fi prezentă cu diferite tablouri clinice, de la vârsta de nou-născut până la adolescență. Nou-născuții cu greutate la naștere sub $2 \mathrm{~kg}$ și cu CoA au risc crescut de a dezvolta hemoragie intraventriculară (HIV) severă, comparativ cu cei din cohorta cu greutate normală la naștere.

Prezentare de caz. Prezentăm cazul unui prematur de sex masculin, cu greutate mică la naștere, care la vârsta de 3 săptămâni dezvoltă semne și simptome de șoc cardiogen. Examenul clinic, ecocardiografia și examenul angio-CT confirmă diagnosticul de CoA severă, fără flux vizibil în canalul arterial. A fost inițiat imediat tratament cu prostaglandină E1, pentru permeabilizarea canalului arterial. Tensiunea arterială sistolică a fost peste percentila 99 pentru vârsta gestațională, iar gradientul nonivaziv între membrul superior și cel inferior a fost de circa $86 \mathrm{mmHg}$. Ecografia transfontanelară decelează hemoragie intraventriculară grad II/III, bilateral, în resorbție, cu transformare chistică. La vârsta de 6 săptămâni, sugarul a beneficiat de corecția chirurgicală a CoA. La reevaluarea de 3 luni postoperator, pe baza semnelor clinice, s-a ridicat suspiciunea de recoarctație de aortă, confirmată prin ecocardiografie și angio-CT. Pacientul prezenta hipertensiune arterială, cu diferență de tensiune între membrele superioare și cele inferioare de circa $37 \mathrm{mmHg}$. A fost realizată corecție chirurgicală, de această dată prin angioplastie de lărgire cu petec. Evoluția postoperatorie a fost grevată de prezența hipertensiunii arteriale, pentru care a necesitat tratament continuu cu inhibitor de enzimă de conversie.

Concluzii. Prematurii cu greutate mică asociată cu CoA corectată chirurgical au un risc ridicat de recoarctare, hipertensiune arterială secundară și hemoragie cerebrală. Un punct important în soluționarea acestor cazuri îl reprezintă echipa medicală multidisciplinară, pentru evaluarea, managementul, dar și prognosticul pacienților.
\end{abstract}

Cuvinte cheie: coarctație de aortă, hemoragie intraventriculară, prematuritate, greutate mică la naștere

\section{INTRODUCERE}

Prezența bolilor congenitale cardiace este de aproximativ $28 \%$ din toate anomaliile congenitale majore [1]. În lume, incidența bolilor cardiace congenitale este estimată la 8/1.000 nou-născuți vii [2]. Coarctația de aortă (CoA) este prezentă la 6-8\% dintre pacienții cu boală congenitală cardiacă, cu o incidență de 4/10.000 nou-născuți vii [3]. Este mai frecventă la sexul masculin și a patra cea mai frecventă leziune care necesită cateterism cardiac sau intervenție chirurgicală în primul an de viață [4]. Cel mai frecvent, coarctația de aortă se prezintă sub forma unei stenoze la nivelul aortei toracice sau în apropierea inserției canalului ar- terial [4]. Etiologia CoA nu este pe deplin înțeleasă. Există două teorii: cea hemodinamică, care include flux sanguin redus prin aortă în perioada fetală, și teoria legată de migrarea țesutului în exces de la nivelul canalului arterial la nivelul istmului aortic [4]. CoA poate să apară izolată, în asociere cu valva aortică bicuspă sau cu malformații cardiace majore [5]. Poate să se prezinte sub diferite tablouri clinice, în funcție de severitatea îngustării aortei, de la vârsta de nounăscut până în adolescență [6]. Majoritatea cazurilor de coarctație de aortă sunt diagnosticate în copilărie, sub $25 \%$ sunt recunoscute după vârsta de 10 ani [5]. În prezența suspiciunii clinice de coarctație de aortă, ecocardiografia este metoda cel mai larg disponibilă 
metodă de diagnostic. Se folosește atât în evaluarea inițială, cât și în perioada postoperatorie.

În ceea ce privește managementul CoA la copii, există două metode terapeutice. Prima, intervenția chirurgicală, reprezintă metoda terapeutică standard a CoA încă din anul 1940. Cea de-a doua metodă este reprezentată de angioplastia cu balon, prin care se stentează locul de coarctație. Cea de-a doua metodă se folosește în special la adolescenți și adulți [5].

Rezultatul corecției chirurgicale timpurii a malformațiilor cardiace la cei cu greutate mică la naștere s-a îmbunătățit în ultimii ani. În ceea ce privește corecția CoA, la nivel mondial există două strategii: una prin care se temporizează intervenția chirurgicală până ce nou-născutul/sugarul atinge o greutate optimă; și cea de-a doua strategie, care este în favoarea corecției chirurgicale timpurii. În ciuda experienței vaste a dilatării cu balon transcateter, corecția chirurgicală rămâne metoda de elecție, în special la nounăscuți. Multe centre au raportat o rată a mortalității postcorecție chirurgicală scăzută și acceptabilă, chiar și la sugarii mici [7]. Fără tratament, prognosticul pacienților cu CoA este nefavorabil. Decesul poate fi cauzat de insuficiența cardiacă congestivă, disecția aortică sau ruptura aortică, endocardita și sângerarea intracraniană, toate ca efecte secundare ale CoA [4].

Hemoragia intraventriculară la copii adesea cauzează decesul sau retard neurologic, psihic și/sau motor. Există asociere între prezența coarctației de aortă și hemoragia intracraniană, fie din cauza hipertensiunii arteriale prelungite, a coexistenței unui anevrism sau a unei combinații între cele două. Prematurii și cei cu greutate mică la naștere au o imaturitate și o fragilitate a vascularizației cerebrale, astfel sunt cu risc crescut de hemoragie intraventriculară spontană [6]. Nou-născuții cu greutate la naștere sub $2 \mathrm{~kg}$ și cu CoA au risc crescut de a dezvolta hemoragie intraventriculară severă, comparativ cu cei din cohorta cu greutate normală la naștere [7].

\section{PREZENTARE DE CAZ}

\section{Istoric}

Prezentăm cazul unui prematur de sex masculin, provenit din sarcină nedispensarizată, născut la nivel teritorial, la vârsta gestațională 34-35 săptămâni, cu greutate mică la naștere (1.680 g), scor APGAR 9 la 1 minut. Din istoricul personal, reținem că, la vârsta de 3 săptămâni, nou-născutul a devenit instabil hemodinamic, cu sindrom funcțional respirator marcat, paloare muco-tegumentară, puls femural slab perceptibil, fără sindrom inflamator biologic pe datele de laborator, necesitând ventilație mecanică. Clinic, s-a ridicat suspiciunea de coarctație de aortă. Ecocardiografia a descris coarctație severă de aortă istmică, cu hipertrofie ventriculară stângă și valvă aortică bicuspă. Angiografia CT a pus în evidență coarctație de aortă, distal de emergența arterei subclaviculare stângi, cu diametru de $4 \mathrm{~mm}$ la nivelul aortei istmice (scor z: -2,24) și dilatare poststenotică, fără evidențierea fluxului la nivelul canalului arterial (figura 1).

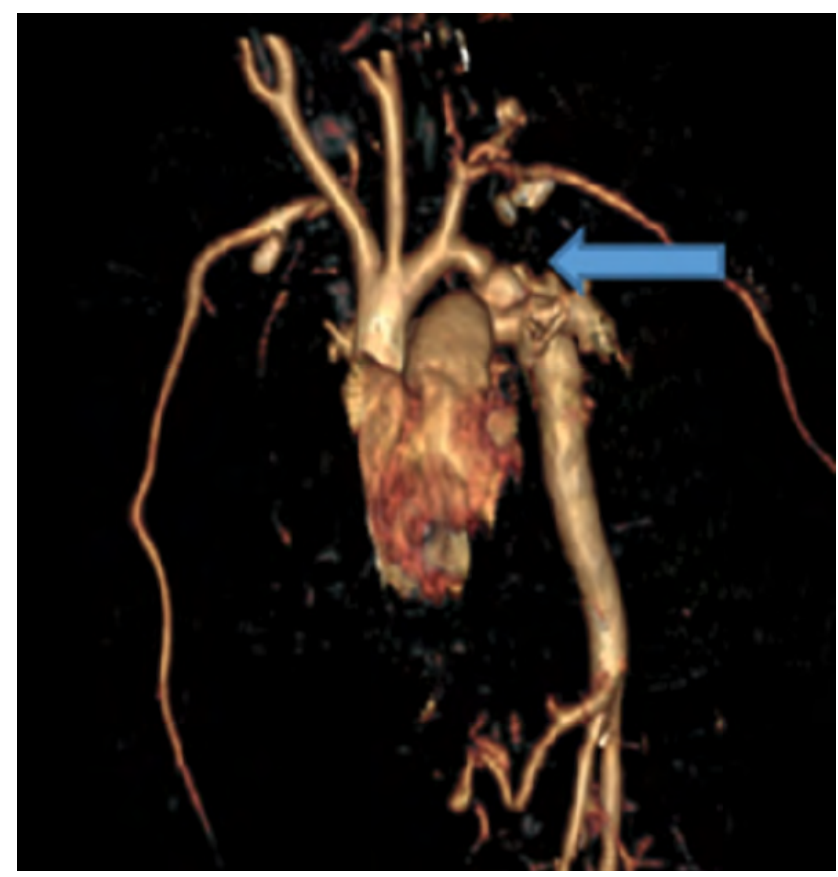

FIGURA 1. Angiografie CT: Coarctație de aortă distal de emergența arterei subclaviculare stângi, cu dilatare poststenotică

S-a inițiat tratament cu prostaglandină E1, pentru repermeabilizarea canalului arterial și îmbunătățirea perfuziei aortei descendente, diuretic și continuarea suportului mecanic respirator, de tip SIMV.

\section{Examen clinic}

La vârsta de 6 săptămâni, sugarul a fost transferat, cu aero-ambulanţa, în clinica noastră, departamentul de terapie intensivă. Starea generală era critică. Sugarul era palid, hipoterm, cu transpirații profuze, sindrom funcțional respirator moderat, saturaţia oxigenului de 96\%, tahicardic, un suflu sistolic de ejecție de grad III/6 s-a decelat la baza cordului și posterior, în zona interscapulară. Pacientul prezenta hepatomegalie, absența pulsului femural bilateral, hemoragie conjunctivală dreaptă, fontanela anterioară largă (6/7 $\mathrm{cm})$, în tensiune, cu suturi craniene dehiscente, status iritabil, dar cu răspuns bun la stimuli, intubat oro-traheal și ventilat mecanic. Tensiunea sistolică era crescută (peste percentila 99 pentru vârsta gestațională [10]), cu diferență de tensiune între membrul superior şi cel inferior de aproximativ $86 \mathrm{mmHg}$. 


\section{Examen paraclinic}

Examenul de laborator pune în evidență acidoză metabolică, hipopotasemie, anemie și hipoglicemie ușoară, fără semne de sindrom inflamator biologic, cu funcție renală și hepatică normală, fără coagulopatii. Electrocardiograma descrie ritm sinusal, cu frecvență cardiacă 150 bătăi/minut, hipertrofie ventriculară și atrială stângă. Radiografia toracică postero-anterioară descrie cardiomegalie (indice cardio-toracic 0,61), cu un contur anormal al arcului aortic.

Ecocardiografia transtoracică 2D și Doppler pune în evidență modificări tipice ale coarctației de aortă. Astfel, din fereastra subcostală, aorta abdominală examinată cu Doppler pulsat arată o velocitate scăzută a fluxului, cu persistența gradientului în diastolă. Evaluarea din fereastra suprasternală pune în evidență îngustarea aortei descendente, imediat sub originea arterei subclaviculare stângi, cu uşoară hipoplazie a aortei transverse (scor z: -2,5) și un flux minim la nivelul canalului arterial. $\mathrm{Cu}$ ajutorul Doppler-ului continuu în sistolă și diastolă, am măsurat velocitatea și gradientul maxim de la nivelul locului de coarctație $(4,71 \mathrm{~m} / \mathrm{s}$ și $89 \mathrm{mmHg})$. S-au pus în evidență valva aortică bicuspă, nestenotică, și mică discontinuitate la nivelul septului interatrial. Din secțiunea apical patru camere și parasternal ax lung, evaluarea mărimii și funcției ventriculare a descris o hipertrofie biventriculară importantă, cu disfuncție sistolică moderată (figura 2).

Având în vedere factorii de risc - prematuritate, aspectul fontanelei anterioare şi valorile ridicate ale tensiunii arteriale -, sugarul a beneficiat de ecografie transfontanelară, care descrie hemoragie intraventriculară bilaterală grad II/III, în resorbție, cu transformare chistică (figura 3 ).

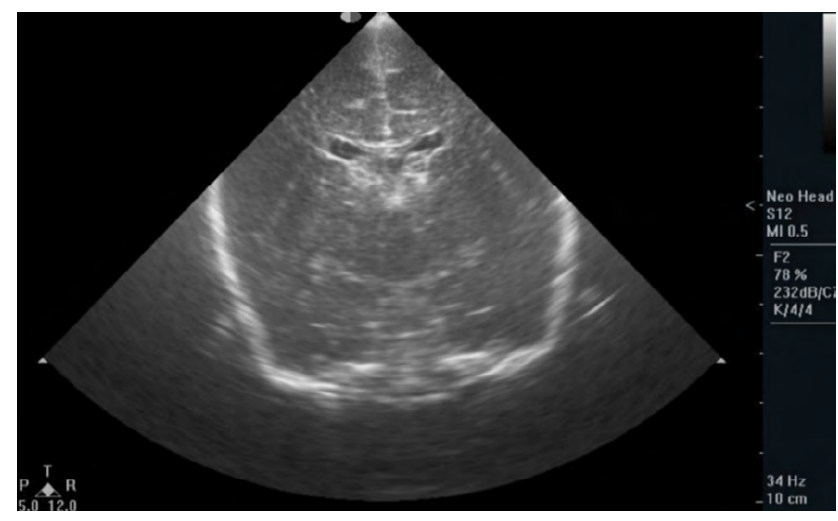

FIGURA 3. Ecografie transfontanelară cu imagine de hemoragie intraventriculară bilaterală, cu transformare chistică

Consultul neurologic stabilește diagnosticul de leziune hipoxică perinatală, sindrom hipoton și hemoragie intraventriculară în resorbție, pentru care au fost recomandate neuroroborante și tratament depletiv. Pacientul asociază sinus dermal sacral pentru care consultul neurochirurgical recomandă RMN lombosacral, care din motive tehnice era indisponibil în acel moment.

\section{Diagnostic}

Diagnosticul stabilit la acel moment a fost următorul: coarctație severă de aortă istmică, hipoplazie uşoară de arc aortic, canal arterial persistent restrictiv, valva aortică bicuspă nestenotică, defect septal atrial mic de tip ostium secundum, hipertensiune arterială secundară, hemoragie intraventriculară în resorbție, leziune hipoxică perinatală și sindrom hipoton, la un sugar prematur.

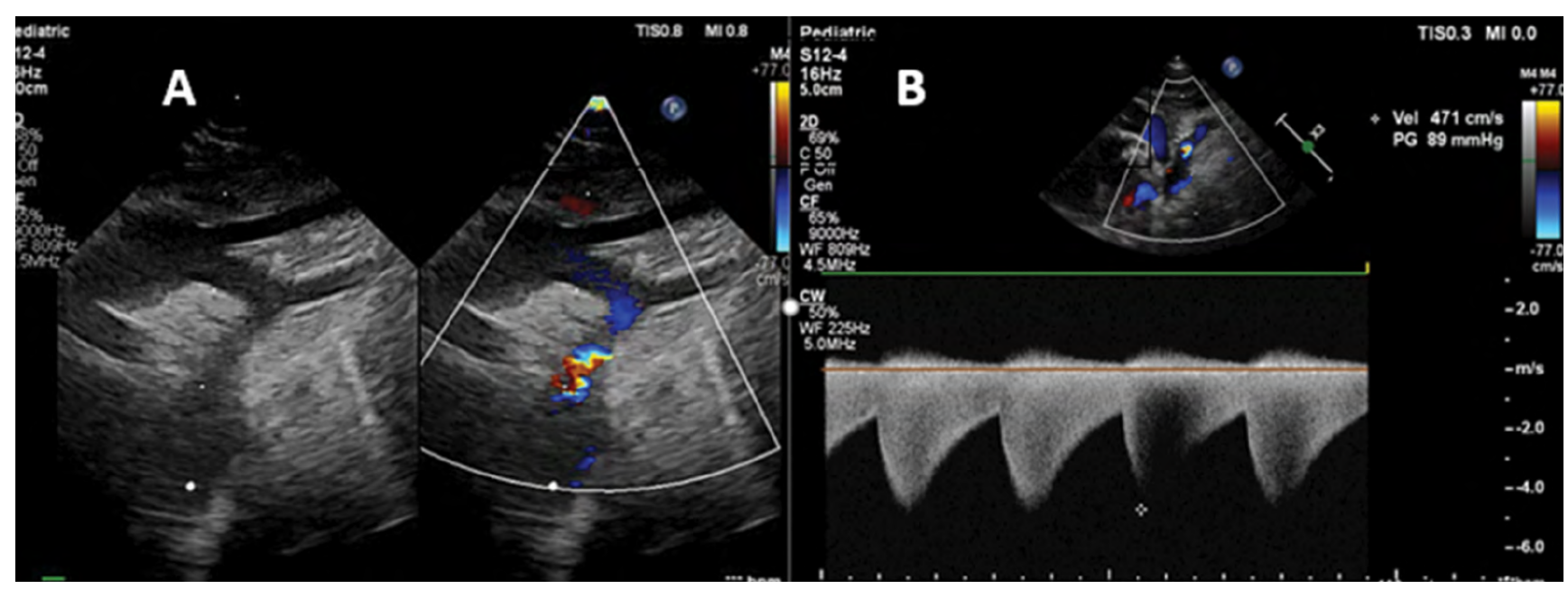

FIGURA 2. Ecocardiografie, fereastră suprasternală. A - Imagine „color compare“- Coarctație de aortă istmică cu ușoară hipoplazie de aortă transversă. B - Doppler continuu cu velocitate și gradient maxim la nivelul coarctației 


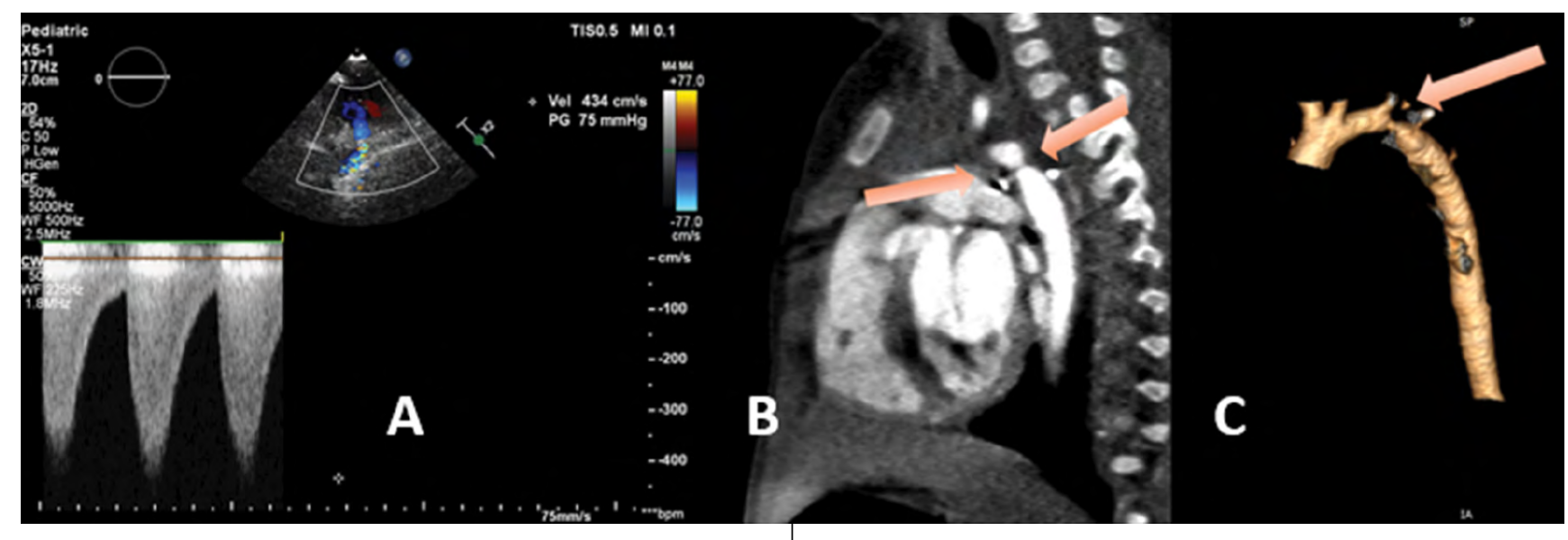

FIGURA 4. A - Ecocardiografie, fereastră suprasternală Doppler continuu cu velocitate și gradient maxim la nivelul coarctației. B - Angiografie CT toracică, secțiune sagitală a situsului coarctației. C - Aorta văzută la angio CT-3D.

\section{Tratament}

După o scurtă perioadă de timp necesară stabilizării pacientului în departamentul de terapie intensivă (corectarea acidozei metabolice, a hipotermiei și hipoglicemiei), a fost efectuată corecția chirurgicală a coarctației de aortă (constând în rezecția zonei stenozate, aortoplastie cu petec de pericard heterolog și anastomoză termino-terminală) și ligatura canalului arterial, prin abord laterotoracic stâng.

\section{Evoluția postoperatorie și complicații}

În evoluția postoperatorie, pacientul a prezentat valori elevate ale tensiunii arteriale, necesitând tratament cu inhibitor de enzimă de conversie și diuretic. Chiar și la doze maximale, nu am putut controla hipertensiunea arterială, motiv pentru care inhibitorul de enzimă de conversie a fost schimbat cu betablocant, cu menținerea diureticului, cu răspuns terapeutic favorabil. Ecocardiografiile postoperatorii seriate au descris gradient sistolic rezidual la nivelul aortei istmice de $20 \mathrm{mmHg}$. Ecografia transfontanelară de control a fost fără imagine de hipertensiune intracranială sau hemoragie intraventriculară acută.

Evoluția postoperatorie a fost lent favorabilă, sugarul fiind externat în ziua 18 postoperator, în stare generală bună, stabil hemodinamic, cu saturații al oxigenului în aerul ambiental de 99\%, frecvență cardiacă 130 bătăi/minut, în ritm sinusal, fără hepatomegalie, curbă ponderală ascendentă, cu toleranță digestivă bună şi tensiune arterială controlată medicamentos (74/41 mmHg) cu betablocant (Propranolol 1,6 mg/ kg/zi) şi doză mică de diuretice (spironolactonă și hidroclorotiazidă), cu status neurologic îmbunătățit.

\section{Reevaluare postoperatorie}

La 3 luni postoperator, sugarul s-a prezentat la reevaluare cu status clinic deteriorat. Pacientul era pa- lid, fontanela anterioară largă, normotensivă, cu sindrom funcțional respirator ușor/moderat, saturația oxigenului în aerul ambiental 97\%, tahicardic, cu hepatomegalie, puls femural slab perceptibil bilateral, cu toleranță digestivă păstrată. Tensiune sistolică la membrele superioare era peste percentila 99 pentru vârsta gestațională, cu diferențe de tensiune între membrele superioare $(142 / 73 \mathrm{mmHg})$ și inferioare $(105 / 87 \mathrm{mmHg})$ de aproximativ $37 \mathrm{mmHg}$. Am ridicat suspiciunea clinică de recoarctație de aortă, confirmată ulterior prin ecocardiografie (restenozarea aortei istmice, cu velocitate de $4,34 \mathrm{~m} / \mathrm{s}$ și gradient 75 $\mathrm{mmHg}$ la acest nivel, măsurate cu ajutorul Dopplerului continuu) şi angio-CT (recoarctația aortei istmice, cu diametrul de 1,2 $\mathrm{mm}$ la acest nivel) (figura 4).

În aceste condiții, presiune arterială crescută și recoarctație de aortă, sugarul a fost reevaluat neurologic, fără a se pune în evidență modificări patologice suplimentare față de evaluările precedente, fără semne de hipertensiune intracranială sau hemoragie acută la ecografia transfontanelară.

În aşteptarea reintervenției chirurgicale, având în vedere valorile tensionale elevate, am reajustat doza de betablocant (la $1,6 \mathrm{mg} / \mathrm{kg} / \mathrm{zi})$ și am asociat inhibitor de enzimă de conversie (Captopril). Ulterior, după stabilizare, sugarul a beneficiat de corecție chirurgicală cu plastie de aortă descendentă cu petec. Ecocardiografiile postoperatorii au evidențiat gradient sistolic rezidual de $19 \mathrm{mmHg}$. În evoluţia postoperatorie, s-au menținut valori elevate ale tensiunii arteriale, motiv pentru care s-a continuat tratamentul cu inhibitor de enzimă de conversie.

\section{DISCUȚII}

În coarctația de aortă, prezentarea clinică şi modificările găsite la examenul obiectiv variază în funcție de vârsta pacientului. În general, prezentarea la o vâr- 
stă fragedă presupune manifestarea severă a bolii. Nou-născuții sunt în general asimptomatici imediat după naștere ca urmare a prezenței canalului arterial, care asigură perfuzia adecvată prin aorta descendentă, indiferent de severitatea coarctației de aortă [4]. În cazul prezentat, prematurul cu coarctație severă de aortă a prezentat semne și simptome de șoc cardiogen doar în momentul închiderii canalului arterial.

Mehwald și colab. au descris un caz asemănător, al unui sugar de sex masculin, în vârstă de 31 de zile, fără antecedente personale patologice, care s-a prezentat în serviciul lor de urgență cu agitație, tahipnee, opistotonus, fontanela anterioară în tensiune, pulsuri femurale nepalpabile bilateral și diferențe de tensiune arterială între membrele superioare și cele inferioare de $100 \mathrm{mmHg}$. La ecografia transfontanelară, s-a decelat hemoragie cerebrală, iar ecocardiografia a pus în evidență CoA severă. În acest caz, s-a practicat corecția chirurgicală a CoA şi şunt ventriculoperitoneal pentru drenajul unui hematom intracerebral, ce a provocat hipertensiune intracerebrală [11].

Cele mai frecvente cauze ale hemoragiei cerebrale la nou-născuți sunt malformațiile arterio-venoase, urmate de coarctația de aortă. Numeroase cauze posibile ale creșterii riscului de hemoragie intraventriculară în prezența coarctației de aortă au fost cercetate [9]. Un prim factor de risc identificat de mai multe studii este expunerea prelungită la valori tensionale elevate. Prematurii și cei cu greutatea la naștere mică au vascularizația cerebrală imatură și, în consecință, mai fragilă, având un risc crescut de hemoragie intracranială spontană. Stresul adițional dat de hipertensiunea arterială asupra acestor vase de sânge le poate face mai susceptibile de hemoragie. Un al doilea factor de risc este necesitatea menținerii patenței canalului arterial, care duce la ischemie cerebrală dată de șuntul din canal. Un al treilea factor de risc poate fi tratamentul cu prostaglandină E1, care poate induce hemoragie intraventriculară prin disfuncția plachetară [12]. Pacientul nostru a prezentat nu doar prematuritate şi greutate mică la naștere, dar și coarctație severă de aortă, cu necesitatea menţinerii canalului arterial permeabil cu prostaglandină E1, hipertensiune arterială secundară. Din cauza faptului că nu avem examen CT cranian, nu putem exclude prezența anevrismelor cerebrale. Întârzierea diagnosticului și corecției chirurgicale a coarctației de aortă prelungește expunerea la acești factori de risc importanți în apariția hemoragiei intraventriculare.

Young și colab. au descris două cazuri similare, ale unor prematuri de sex masculin, la care manifestările neurologice și prezența hipertensiunii arteriale sistemice marcate au dus la diagnosticarea CoA. Aceștia au atras atenția asupra diagnosticului de CoA care poate fi trecut cu vederea dacă nu există un grad ridicat de suspiciune [13].

În general, se consideră că o greutate mică la naștere nu este contraindicație pentru corecția timpurie a malformațiilor cardiace. Rata mare de mortalitate a fost raportată la nou-născuții și sugarii care nu au beneficiat de corecția CoA. Sudarshan şi colab. au evaluat retrospectiv 24 de nou-născuți/sugari cu greutatea sub $2 \mathrm{~kg}$, la care s-a intervenit chirurgical pentru CoA, pe o perioadă de 15 ani [7]. Corecția efectuată pentru toți acești pacienți a fost cea chirurgicală, cu rezecția zonei de îngustare. Recoarctația aortei s-a dezvoltat doar la 7 pacienți. Analiza factorilor de risc a arătat că prezența preoperatorie a insuficienței cardiace congestive, coexistența unor leziuni noncardiace, durata prelungită a clampării aortei intraoperator și ventilația postoperatorie au o mare influență asupra ratei de mortalitate postoperatorie. Mai mult, McElhinney și colab. au concluzionat că o greutate mică la momentul intervenției chirurgicale nu este un factor de risc pentru recoarctație [14]. Totuși, Bacha și colab. afirmă că cei cu greutate mică (sub $1,5 \mathrm{~kg}$ ) la momentul intervenției chirurgicale au un risc semnificativ mai mare pentru gradient rezidual la nivelul CoA sau dezvoltarea recoarctației [15].

În cazul prematurului prezentat, prima intervenție chirurgicală a fost înainte de 2 luni de viață. Drept urmare, la mai puțin de 3 luni de la prima intervenție, a dezvoltat recoarctație de aortă.

Baykan şi colab. au descris trei cazuri ale unor copii cu hipertensiune arterială și accident vascular cerebral, care asociau CoA nediagnosticată și netratată. Concluzia acestora a fost că trebuie ridicată suspiciunea de CoA la orice pacient cu hipertensiune arterială [6]. Sunt necesare investigații suplimentare pentru elucidarea etiologiei și a cauzelor de hipertensiune arterială secundară.

Prognosticul pe termen lung al pacienților care au beneficiat de corecție chirurgicală pentru coarctație de aortă este mai prost față de populaţia generală, în mare parte ca urmare a efectelor pe termen lung ale hipertensiunii arteriale persistente [4]. Mai mult, hemoragia intraventriculară este asociată cu rezultate funcționale neurologice slabe [16].

\section{CONCLUZII}

Nou-născuții prematuri cu greutate scăzută la naştere au constituit întotdeauna o provocare în managementul medical, cu implicaţii atât pe termen scurt, cât și lung. În cazul descris, am prezentat un nou-născut prematur, născut cu greutate mică, diagnosticat cu CoA critică și am expus provocările cu care ne-am confruntat în procesul de stabilizare a nou-născutului. 
În astfel de cazuri de prematuri cu greutate mică, asociată cu CoA corectată chirurgical, există un risc ridicat de recoarctare, hipertensiune arterială secundară și hemoragie cerebrală. Concluziile noastre ar putea să îi ajute pe medici să prevadă complicațiile postoperatorii și să optimizeze strategiile terapeutice și, de ase-

\section{BIBLIOGRAFIE}

1. Dolk H, Loane M, Garne E. European Surveillance of Congenital Anomalies (EUROCAT) Working Group. Congenital heart defects in Europe: prevalence and perinatal mortality, 2000 to 2005 . Circulation. 2011;123(8):841-849.

2. Bernier PL, Stefanescu A, Samoukovic G, Tchervenkov Cl. The challenge of congenital heart disease worldwide: Epidemiologic and demographic facts. Semin Thorac Cardiovasc Surg Pediatr Card Surg Annu. 2010;13(1):26-34.

3. Mason CA, Kirby RS, Sever LE, Langlois PH. Prevalence is the preferred measure of frequency of birth defects. Birth Defects Res A Clin Mol Teratol. 2005;73(10):690-692.

4. Beekman R. Coarctation of the Aorta. In: Allen H, Shaddy E, Penny F, Feltes T, Cetta F. Moss and Adams' Heart Disease in Infants, Children, and Adolescents: including the fetus and young adult. 9th ed. Lippincott Williams \& Wilkins; 2016:1107-1125.

5. Doshi A, Rao S. Coarctation of aorta-management options and decision making. Pediat Therapeut. 2012;S5-006.

6. Baykan A, Argun M, Ozyurt A, Pamukçu O, Uzüm K, Narın N. Hypertension associated with coarctation of the aorta revisited: Case-based update from experience of three children. Case Rep Pediatr. 2013;2013:716438.

7. Sudarshan CD, Cochrane AD, Jun ZH, Soto R, Brizard CP. Repair of coarctation of the aorta in infants weighing less than 2 kilograms. Ann Thorac Surg. 2006;82(1):158-163.

8. Stoll BJ, Hansen NI, Bell EF et al. Neonatal outcomes of extremely preterm infants from the NICHD Neonatal Research Network. Pediatrics. 2010;126(3):443-456. menea, evoluția postoperatorie în unitatea de terapie intensivă. Un punct important în soluționarea acestor cazuri este echipa medicală multidisciplinară, pentru evaluarea, managementul, dar și prognosticul pacienților.

Conflict of interest: none declared Financial support: none declared

9. Seckeler MD, White SC, Fox KA. Increased risk of intraventricular hemorrhage in low birth weight infants with aortic coarctation. $J$ Matern Fetal Neonatal Med. 2020;33(8):1273-1275.

10. Nickavar A, Assadi F. Managing hypertension in the newborn infants. Int J Prev Med. 2014;5(Suppl 1):S39-S43.

11. Mehwald PS, Dittrich S, Grohmann J, Bley T, Kececioglu D. Coarctation of the aorta presenting as cerebral hemorrhage. J Pediatr. 2005;146(2):293.

12. Brunner B, Hoeck M, Schermer E, Streif W, Kiechl-Kohlendorfer U. Patent ductus arteriosus, low platelets, cyclooxygenase inhibitors, and intraventricular hemorrhage in very low birth weight preterm infants. J Pediatr. 2013;163(1):23-28.

13. Young RS, Liberthson RR, Zalneraitis EL. Cerebral hemorrhage in neonates with coarctation of the aorta. Stroke. 1982;13(4):491-494.

14. McElhinney DB, Yang SG, Hogarth AN et al. Recurrent arch obstruction after repair of isolated coarctation of the aorta in neonates and young infants: Is low weight a risk factor? J Thorac Cardiovasc Surg. 2001;122:883-90.

15. Bacha EA, Almodovar M, Wessel DL et al. Surgery for coarctation of the aorta in infants weighing less than $2 \mathrm{~kg}$. Ann Thorac Surg. 2001;71(4):1260-1264.

16. Li Q, Huang YJ, Zhang G et al. Intraventricular Hemorrhage and Early Hematoma Expansion in Patients with Intracerebral Hemorrhage. Sci Rep. 2015;5:11357. 